\title{
Zamanla Değişen Parametreli Genişletilmiş Taylor Kuralı: Türkiye için Finansal İstikrarın Rolü
}

\author{
Kübra COŞAR*, Nezir KÖSE*
}

Öz

Bu çalışmada, finansal ve ekonomik göstergeler kullanılarak faktör analizi çerçevesinde Türkiye için 2002-2017 dönemlerini kapsayan aylık finansal istikrar endeksi hesaplanmıștır. Zamanla değișen parametreli Taylor eșitliği finansal istikrar endeksi ile genişletilmiştir. Kalman Filter Yöntemi ile tahmin edilen genişletilmiş Taylor eşitliğinden elde edilen bulgular, Türkiye Cumhuriyet Merkez Bankası politika faiz oranının finansal istikrar göstergesinden etkilendiğini göstermiştir.

Anahtar Kelimeler: Enflasyon Hedeflemesi Rejimi, Genişletilmiş Taylor Kuralı, Finansal İstikrar, Faktör Analizi Yöntemi, Para Politikası

\section{Time Varying Parameter Augmented Taylor Rule: The Role of Financial Stability for Turkey}

\section{Abstract}

In this paper, monthly financial stability index has been constructed by economic and financial indicator for the term 2002-2017. Taylor Rule with time-varying parameter was augmented by the financial stability index. According to result of augmented Taylor Rule estimated by Kalman Filter Method, Central Bank of the Republic of Turkey's policy rate was influenced by the financial stability index.

Keywords: Inflation Targeting Regime, Augmented Taylor Rule, Financial Stability, Factor Analysis Method, Monetary Policy

\section{Özgün Araștırma Makalesi (Original Research Article)}

Geliş/Received: 17.12 .2018

Kabul/Accepted: 04.03.2019

DOI: http://dx.doi.org/10.17336/igusbd.495528

*Arș. Gör., Ankara Hacı Bayram Veli Üniversitesi, İktisadi ve İdari Bilimler Fakültesi, Ekonometri Bölümü, Ankara, Türkiye, E-posta: kubra.cosar@hbv.edu.tr ORCID ID http://orcid.org/0000-00030676-0548

${ }^{* *}$ Prof. Dr., İstanbul Gelişim Üniversitesi, İktisadi İdari ve Sosyal Bilimler Fakültesi, Ekonomi ve Finans Bölümü, İstanbul, Türkiye, E-posta: nkose@gelisim.edu.tr ORCID ID http://orcid.org/0000$\underline{0002-4127-357 X}$ 


\section{Giriş}

Küreselleşen ekonomi ile birlikte ülkelerin de para politikalarını yeniden düzenlemesi ihtiyacı doğmuş, 1980'li yıllarda dünyada finansal piyasalarda başlayan yenilikler 1990'larda hız kazanmış ve önceden bir politika belirlemeye temel olabilecek parasal ilișkileri tahmin etmek zorlașmıştır. 1990'larda ilk kez Yeni Zelanda enflasyon hedeflemesi rejimini uygulamış, başarılı olması üzerine sonraki yıllarda Kanada (1991), İngiltere (1992), İsveç, Finlandiya ve Avustralya (1993) enflasyon hedeflemesi rejimi uygulamaya başlamıș ve sonrasında bu ülkeleri Çekya, Brezilya, İsrail, Şili gibi ülkeler de takip etmiștir (Svensson, 2002, s.771).

Kasım 2000 krizinin ardından yaşanan siyasi gerilim sonucunda Türkiye Ekonomisi 19 Şubat 2001 tarihinde ikinci bir kriz yaşamıștır. Bundan sonra yaşanan olumsuz gelişmeler neticesinde enflasyon \%88,6 seviyesine çıkmıştır. GSYİH, işsizlik oranı gibi birçok makroekonomik gösterge önemli derecede bozulmuştur. Kasım 2000'de yaşanan likidite krizi sonrası Hükümetin IMF ile imzalamış olduğu Aralık 2000 tarihli Dördüncü Niyet Mektubu'nda Enflasyon Hedeflemesi Rejimine geçileceği belirtilmiş, Hükümet Türkiye Cumhuriyet Merkez Bankası'nın fiyat istikrarı hedefine ulaşması ve sürdürebilmesi için, Türkiye Cumhuriyet Merkez Bankası (TCMB) Yasasında gerekli düzenlemeleri yapacağını taahhüt etmiştir. Bütün bu gelişmelerin ardından "Güçlü Ekonomiye Geçiş Programı" devreye sokulmuştur. Güçlü Ekonomiye Geçiş Programı sürecinde 1211 sayılı TCMB Kanununun bazı maddeleri değiștirilerek 25 Nisan 2001 tarihinde 4651 sayılı Kanun TBMM Genel Kurulu'nda kabul edilmiștir. Bu Kanun ile fiyat istikrarının sağlanması hedeflenirken enflasyon hedeflemesi rejimine geçilmesi yolunda gerekli yasal düzenlemeler yapılmıştır. Kanun ile TCMB'nin şeffaflığı ve hesap verebilirliği artırılırken, hükümet ile belirlenecek enflasyon hedeflemesine ulaşmada ve faiz politikasını belirlemede tam bağımsızlığı sağlanmıştır (Çetin, 2016). İlk aşamada Türkiye'de enflasyon hedeflemesi rejimine geçilmesi için koşullar uygun olmadı̆̆ından, 2001 yılında örtük enflasyon hedeflemesi rejimi uygulanmıştır. Başarılı sonuçlar elde edilmesinin ardından 2006 yılından sonra enflasyon hedeflemesi rejimi çerçevesinde, para politikası fiyat istikrarını sağlamayı amaçlayan esnek enflasyon hedeflemesi stratejine geçmiştir. Uygulanan strateji enflasyonla mücadelede büyük katkılar sağlamış uzun yıllardan sonra enflasyon tek haneli rakamlara düşmüştür (Başçı \& Kara,2011,s.11).

Eylül 2008'de gelişmiş ülkelerde başlayıp, Kasım 2008'de gelişmekte olan ülkelerde de etkisini gösteren küresel kriz sonrasında ortaya çıkan yeni konjonktür merkez banklarının yeni bir para politikası geliștirmesi gerekliliğini ortaya koymuştur. Krizden çıkarılan en önemli ders ise merkez bankalarının reel sektör ve finansal sektörde ortaya çıkabilecek riskleri ve sorunları göz ardı etmemesi gerektiğidir. Bu doğrultuda merkez bankalarının finansal istikrarı da göz önüne alması gerektiği görüşü yaygınlık kazanmıştır. Bu çerçevede TCMB de 2010 yılının sonlarından itibaren fiyat istikrarı ana hedef olarak kalmakla birlikte finansal istikrarı da ikinci bir hedef olarak değerlendirerek esnek enflasyon hedeflemesi rejimi adını verdiğimiz yeni bir para politikası geliştirmiş ve uygulamaya koymuștur (Kara,2012). Uygulamada enflasyon 
hedeflemesi rejimi 'katı' bir para politikası değil 'esnek' bir uygulama olarak kullanılmaktadır (Bernanke \& Mishkin, 1997).

Öte yandan para politikasının bir kurala göre uygulanıp uygulanamayacağı başka bir tartışma konusuyken, özellikle enflasyon hedeflemesi rejiminin genel yapısı ve uygulanması açısından uyumlu bir çerçeve içinde olması nedeniyle de para politikasının bir kurala göre uygulanması yönünde fikir birliği sağlanmıștır. Çünkü bir kurala göre kalarak para politikasının uygulanması, enflasyon hedeflemesi rejimini de desteklemektedir. Bu yüzden enflasyon hedeflemesi rejimi uygulayan ülkelerin birçoğu para politikasını bir kural ekseninde yürütmektedirler (Ardor \& Varlık, 2014). Diğer bir ifade ile enflasyon hedeflemesi rejimi hem "kurala göre" hem de "duruma göre" hareket edebilmektedir. $\mathrm{Bu}$ yüzden bu stratejiye kural benzeri (rule-like) para politikası da denilmektedir (Hammond, 2012, s. 5-6). Kural benzeri para politikasının uygulanmasında politika aracı olarak kısa vadeli faiz oranlarını kullanması ve enflasyon hedeflemesi rejimini kapsaması yönüyle sıkça Taylor Kuralı ile karşılaşmaktayız. Taylor (1993) çalışması ile tanıştığımız Taylor Kuralı orijinalinde faiz oranı, enflasyon ve çıktı açığı arasında basit doğrusal ilişski kurmaktadır (Castro, 2011). Taylor önerdiği modeli kapalı ekonomi varsayımı ile geliștirmiş ve zaman içerisinde küreselleșen ekonomi ile birlikte Taylor kuralının geçersiz olduğu ve geliştirilmesi gerektiği fikri yaygınlaşmış ve Taylor modeli çeşitli göstergelerle genişletilerek farklı politika önerileri ortaya konulmuştur. Taylor modelinde varlık fiyatlarındaki oynaklık veya döviz kuru gibi tek bir değișken yerine finansal istikrarı yansıtacak toplulaştırılmış bir endeksin kullanılmasının gerçek durumu daha iyi yansıtacağı düşünülmektedir. Çünkü bu tarz bir endeksin oluşturulması bazı avantajları da beraberinde getirecektir. Fiyat istikrarı gibi tek boyutlu olmadığından finansal istikrar birçok faktör tarafından eş zamanlı olarak etkilenmektedir. Bu nedenle finansal istikrarın çok boyutlu olarak ölçülmesi daha uygun olacaktır. Ayrıca çok boyutlu olarak hesaplanan finansal istikrar göstergesi bu göstergenin alt bileşenlerdeki farklı şoklar karşısında merkez bankasının reaksiyon göstermesine de olanak sağlayacaktır (Albulescu, 2013, s.63).

Son zamanlarda Merkez Bankalarının finansal istikrarı gözetmeli midir tartışmasının artması ile birlikte finansal istikrarın tanımlanması, ölçülmesi ve para politikasına dâhil edilmesi önemli bir konu haline gelmiştir. Bu doğrultuda finansal stres, istikrar veya istikrarsızlığın ölçülmesi ve para politikasına dâhil edildiği durumu inceleyen çalışmalarla sık sık karşılaşılmaktadır. Montagnoli ve Napolitano (2005) çalışmasında Amerika Birleşik Devletleri, Kanada, Euro Alanı ve Birleşik Krallık için Kalman yöntemi kullanarak bir finansal koşul göstergesi olușturmuş ve Taylor Kuralını genişleterek bir politika önerisinde bulunmuştur. Akram, Bårdsen ve Lindquist (2007) çalışmasında finansal istikrarı gözeten esnek enflasyon hedeflemesi rejiminin makroekonomik etkileri araştırılmış, para politikası kuralı finansal istikrar göstergesi ile genişletilmiştir. Bauducco, Bulíř ve Čihák, (2008) çalışmasında ise merkez bankalarının finansal istikrarsızlığa tepki vermesi durumunda enflasyon ve çıktı açı̆̆ının istikrarını daha iyi sürdürebildiğini göstermişlerdir. Castro (2011) çalışmasında Taylor kuralını finansal koşul indeksi ile genişletmiş ve Avrupa Merkez Bankasının finansal koşullara tepki verdiği sonucuna ulaşmıştır. Woodford (2012) çalışmasında finansal istikrarı göz önüne alan bir para politikasının oluşturulmasını tartışmıştır. Albulescu (2013) 
çalışmasında ise Avrupa Merkez Bankasının para politikası kararında finansal istikrarı hedeflemesi gerektiğine işaret eden bir model kurmuştur. Önerilen modelin bir parçası olarak toplulaștırılmış finansal istikrarsızlık göstergesi oluşturulmuş ve Taylor kuralı bu gösterge ile genişletilmiştir. Elde edilen sonuçlar para politikası kararlarının finansal istikrarsızlıktan etkilendiğini göstermiştir. Baxa, Horváth ve Vašíček (2013) çalışmasında ABD, Birleşik Krallık, Avustralya, Kanada ve İsveç için Finansal Stres Endeksi oluşturmuş ve Taylor kuralına dâhil etmiştir. Cevik, Dibooglu ve Kenc (2016) çalışmasında Endonezya, Güney Kore, Malezya, Filipinler ve Tayland için Finansal Stres Endeksi oluşturmuş ve iktisadi faaliyetlerle olan ilișkisini incelemiştir.

$\mathrm{Bu}$ çalışmada TCMB'nin ikincil bir hedef olarak finansal istikrarı gözetmesi doğrultusunda Taylor Modeli finansal istikrar göstergesi ile genişletilmiştir. Çalışmanın birinci bölümünde finansal istikrar göstergesi ile genişletilmiş Taylor eşitliği hakkında bilgi verilmiștir. İkinci bölümde faktör analizi kullanılarak 2002-2017 yılları arasında aylık frekanslı finansal istikrar göstergesi elde edilmiştir. Üçüncü bölümde ise finansal istikrar göstergesi ile genişletilmiş Taylor eşitliği parametreleri Kalman Filtresi yöntemi ile tahmin edilmiştir. Çalışma ampirik bulguların değerlendirildiği sonuç bölümü ile son bulmaktadır.

\section{Genişletilmiş Taylor Kuralı}

John Taylor (1993) tarafından geliştirilen Taylor kuralı, politika faiz oranı ile çıktı açı̆̆ı ve enflasyon arasındaki ilişkiyi kuran bir para politikası kuralıdır. Taylor eşitliği aşağıdaki gibi tanımlanmıştır.

$\mathrm{i}_{\mathrm{t}}=\alpha+\beta \pi_{\mathrm{t}}+\gamma \mathrm{y}_{\mathrm{t}}$

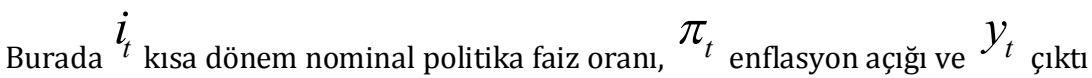
açığıdır. Bu kurala göre enflasyon açığındaki ve çıktı açığındaki artış kısa dönem faiz oranlarını da artıracaktır veya tam tersi geçerlidir. Bu modele en önemli eleştiri modelin kapalı ekonomi varsayımı altında kurulmuş olmasıdır. Çünkü küçük açık ekonomilerde döviz kuru enflasyonu ve çıktı düzeyini etkilemektedir. Ball (1999) ve Svensson (2000) çalışmalarında; döviz kurunun enflasyon üzerinde etkili olması nedeniyle merkez bankası reaksiyon fonksiyonuna yani Taylor eşitliğine eklenmesi gerektiğini savunmuşlardır. Son dönemde merkez bankaları nihai bir hedefe ve tek bir enstrümana sahip olduğu varsayılmıș olsa da, bu merkez bankasının fiyat istikrarına odaklanırken döviz kuru gibi diğer ekonomik değişkenlerde meydana gelecek değişmelere kayıtsız kalacağı anlamına gelmemektedir (Freedman ve Otker-Robe, 2010, s.3-5). Özellikle küçük açık ekonomilerde döviz kuru ithal malların fiyatları ve göreli fiyatlara bağlı olarak enflasyonu ve çıktı açığını etkiler (Adolfson, 2007). Döviz kuru ile faiz oranı arasındaki ilişki varlık fiyatlarını da etkilemektedir (Ball, 1999). Ayrıca yurtiçi firmaların yurtdışındaki rekabet gücü döviz kurundan etkilenmektedir. Buna ek olarak firma ve bankaların büyük oranda yabancı para cinsinden borçlanmış olmaları ve karşılığında yeterince döviz varlıklarının bulunmaması, borç açığının artmasına ve hatta sonunda 
firmaların batmasına neden olabilir (Käfer, 2014). Garcia, Restrepo ve Roger (2011) çalışmasında modele döviz kuru değişkeninin eklenmesinin, risk primi şoklarının ele alınmasında oldukça yararlı olduğu sonucuna varmıştır. Merkez bankaları para politikası kararını alırken sadece döviz kuru değil diğer birçok değişkeni de göz önüne almalıdır. Özellikle küresel krizin ardından merkez bankalarının ikincil bir amaç olarak finansal istikrarı gözetmesiyle birlikte, Taylor kuralının finansal istikrarla genişletilmesi gündeme gelmiştir. Bu makalede de Taylor Kuralı finansal istikrar göstergesi ile genişletilmiş ve denklem aşağıdaki gibi düzenlemiştir:

$$
\mathrm{i}_{\mathrm{t}}=\overline{\mathrm{r}}+\alpha\left(\pi_{\mathrm{t}}-\pi_{\mathrm{t}}^{*}\right)+\beta\left(\mathrm{y}_{\mathrm{t}}-\mathrm{y}_{\mathrm{t}}^{*}\right)+\gamma \mathrm{fs}_{\mathrm{t}}+\mathrm{u}_{\mathrm{t}}
$$

Burada $i_{t}$ kısa vadeli nominal politika faiz oranı, $\pi_{t}$ enflasyon oranı, $\pi_{t}^{*}$ beklenen enflasyon oranı, ${ }^{y_{t}}$ gerçekleşen çıktı düzeyi, ${ }^{*}{ }_{t}^{*}$ potansiyel çıktı düzeyi, $f_{t}$ finansal istikrar göstergesi ve $u_{t}$ hata terimidir. Sırasıyla $\alpha, \beta, \gamma$ ise değişkenlere ait katsayılardır.

\section{Finansal İstikrar Göstergesinin Elde Edilmesi}

Son yıllarda, finansal istikrar ile para politikası arasındaki ilişki çok sık tartışılan bir konu olarak karşımıza çıkmaktadır. Sıklıkla tartışılmasına rağmen finansal istikrar için ortak bir tanım geliştirilememiştir ve buna paralel olarak finansal istikrarın sürdürülebilmesi yönünde hangi politikaların uygulanacağı hakkında da fikir birliği yoktur (Allen \& Wood, 2006, s.152). Finansal istikrar tanımının yapılması istendiğinde, finansal sistemi oluşturan piyasalar ve sistemde yer alan kuruluşlar, diğer ekonomik sistemlerle ilişkisi değerlendirerek tüm riskleri barındıracak şekilde bir tanım geliştirilmelidir. Finansal istikrarın içerisinde birçok risk faktörünü barındırdığı düşünüldüğünde, tüm bu riskleri barındıran tek bir model kurulması mümkün olamayacağına göre, aslında finansal istikrarın tanımı üzerinde uzlaşı beklemek de doğru bir yaklaşım olmayacaktır. Ayrıca finansal istikrarın barındırdığı riskler dinamik bir yapıya sahip olduğundan finansal istikrarı temsil edecek gösterge de zamana göre değişen bir yapıda olacaktır (Aktaş, 2011, s.3). Bu nedenle finansal istikrarı kabaca tanımlamak ve esasında nasıl ölçülebileceği üzerinde yoğunlaşmak daha önemlidir.

Finansal istikrar ele alınırken tüm ekonomik sistemlerle bir arada değerlendirilmeli, çok boyutlu olarak tartışılmalı ve birçok faktör bir arada göz önüne alınmalıdır. Finansal sistemi oluşturan ana değişkenlerin yanı sıra reel ekonominin durumunu yansıtan değişkenler de ele alınmalıdır. Bu doğrultuda Reel Sektör, Borsa, Bankacılık Sektörü ve Dış Ticaret Sektörünü temsilen değişkenler mümkün olduğunca analize dâhil edilmiştir. Küresel risk iştahının en önemli göstergelerinden biri olan VIX endeksi ve ülkenin risklilik düzeyini göstermesi amacıyla ülkenin kamu borç faizini ölçen JP Morgan EMBI+ endeksi finansal istikrar göstergesinin elde edilmesinde dikkate alınmıştır (Rozada \& Yeyati, 2006). İktisat literatüründe finansal sistemin istikrarlı olması ile kastedilen, şoklara karşı kırılganlığın düşük olmasıdır. Finansal piyasalar 
açısından ülkelerin şoklara karşı kırılganlığının göstergesi ise risk primleri olmaktadır. Düşük risk primi, ülkenin görece finansal olarak istikrarlı ve sağlam olduğunu göstermektedir (Carare, Schaechter, Stone \& Zemler, 2002; Das, Papapioannou, Pedras, Ahmed \& Furti, 2010). ABD gibi gelişmiş ülkelerin faiz oranları ise sermaye akımı açısından önem arz etmektedir. Özellikle ABD uzun dönem faiz oranının gelişmekte olan ülkelerin uzun dönem faiz oranları üzerinde önemli bir etkisinin olduğu bazı çalışmalarda ortaya konmuştur (Ferucci, Herzberg, Soussa \& Taylor, 2004; Jeanneau \& Micu, 2002). Bu nedenle faktör analizi ile finansal istikrar endeksinin elde edilmesinde ABD'nin 10 yıllık tahvil getirisi de kullanılmıștır. Bu çalıșmaya eklenmesi önemli olabilecek bazı ekonomik değișkenler zaman serilerinin frekans aralığının aylık olarak belirlenmiş olması ve bu serilerin de çeyreklik dönemde hesaplanarak yayınlanması nedeniyle çalışma kapsamına dâhil edilememiştir. Değişkenlerin belirlenmesinde en önemli kısıtlamalardan bir tanesinin bu olduğu söylenebilir. Finansal istikrar göstergesinin hesaplanmasında kullanılan tüm değişkenler, istikrarı etkileme yönü ve serilerin elde edildiği kaynaklar Tablo 1'de sunulmuştur.

Reel Borsa değişkeni borsa getirisinin enflasyondan arındırılması ile elde edilmiş ve yıllık büyüme oranı hesaplanarak çalışmaya dâhil edilmiştir. Getiri farkı uzun dönem faiz oranından kısa dönem faiz oranının çıkarılmasıyla hesaplanmıştır. Uzun dönem faiz oranına karşılık olarak Bankalarca Açılan Kredilere Uygulanan Ağırlıklı Ortalama Faiz Oranı (Konut, TL üzerinden açılan), Kısa dönem faiz oranına karşılık olarak Bankalarca Açılan Mevduatlara Uygulanan Ağırlıklı Ortalama Faiz oranı (3 aya kadar vadeli, TL üzerinden Açlan Mevduatlar) kullanılmıştır. Büyüme oranı ise Gayri Safi Yurtiçi Hâsıla değişkeninin çeyreklik frekansla yayınlanıyor olması nedeniyle Sanayi Üretim Endeksinden hesaplanmıştır.

\begin{tabular}{|l|l|l|l|}
\hline Kısa Gösterimi & Gösterge & $\begin{array}{l}\text { İstikrarı } \\
\text { etkileme } \\
\text { yönü }\end{array}$ & Veri kaynağı \\
\hline RB & Reel Borsa Getirisi & + & TCMB-evds \\
\hline GF & Getiri farkı & - & TCMB-evds \\
\hline BO & Büyüme oranı & + & Hesaplandı \\
\hline BSKB & Bankacıllk Sektörü Kredi Büyümesi & + & TCMB-evds \\
\hline RSGE & Reel Sektör Güven Endeksi & + & TCMB-evds \\
\hline DTF & Dış Ticaret Fazlası & + & IFS \\
\hline İO & İşizlik Oranı & - & TCMB-evds \\
\hline ENF & Enflasyon Oranı & - & IFS \\
\hline UR & Uluslararası Rezerv Artışı & + & TCMB-evds \\
\hline M2UR & (M2/Uluslararası Rezerv) Artışı & + & TCMB-evds \\
\hline DKO & Reel Efektif Döviz Kuru Oynaklı̆ı & - & Hesaplandı \\
\hline BO & Borsa Oynaklı̆̆ı & - & Hesaplandı \\
\hline VIX & S\&P 500 Hisse Senedi Oynaklı̆ı̆ & - & FRED \\
\hline JP EMBI & JP Morgan Emerging Market Bond Indices & - & Bloomberg \\
\hline ABD10Y & ABD 10 Yıllık Tahvil Getirisi & - & FRED \\
\hline
\end{tabular}

Tablo 1: Finansal istikrar göstergesinin elde edilmesinde kullanılan değişkenler 
Bu çalışmada değişkenler Illing ve Liu (2003) çalışmasında olduğu gibi faktör analizi yöntemi kullanılarak bir göstergeye dönüştürülmesi hedeflenmektedir. Faktör analizi yönteminin tercih edilmiş olmasının en önemli sebebi yöntemin, birbiri ile ilișkili çok sayıdaki değişkenden daha az sayıda birbiri ile ilişkisiz faktör olarak adlandırılan yeni yapay değişkenler üretilmesine olanak sağlamasıdır. Ve diğer yöntemlerden en önemli farkı ürettiği yapay değișkenlerin kavramsal olarak anlamlı olmasıdır (Ișık, Duman \& Korkmaz, 2004). Temelde faktör analizi aralarında yüksek ilișki olan değişkenleri bir araya toplayarak bir grup oluşturur ve bu grupla düşük ilişkili ancak kendi aralarında yüksek ilişkili değişkenlerde başka bir grup oluşturarak değișkenleri faktör adı verilen yeni değişkenlere dönüștürür. Elde edilen faktörler birbiri ile ilişkisizdir ve birinci faktör en yüksek varyans açıklama oranına sahiptir. İkinci faktör birinci faktörden daha az diğer faktörlerden daha çok varyans açıklama oranına sahiptir. Varyans açıklama oranı azalarak devam etmektedir. Varyans açıklama oranı en küçük faktörler göz ardı edilerek boyut indirgeme yapılmaktadır (Johnson ve Wichern, 2007).

\begin{tabular}{|c|c|c|c|}
\hline Değişken Adı & Model & $\begin{array}{l}\text { Test İstatistik } \\
\text { Değeri }\end{array}$ & P Değeri \\
\hline \multirow[b]{2}{*}{ Enflasyon } & Sabit Terimli & $-8,23038$ & $0,0000^{*}$ \\
\hline & Trend ve Sabit Terimli & $-7,63429$ & $0,0000^{*}$ \\
\hline \multirow[b]{2}{*}{ Getiri Farkı } & Sabit Terimli & $-4,37507$ & $0,0004^{*}$ \\
\hline & Trend ve Sabit Terimli & $-4,27838$ & $0,0042^{*}$ \\
\hline \multirow[b]{2}{*}{ Büyüme Oranı } & Sabit Terimli & $-3,60057$ & $0,0066^{*}$ \\
\hline & Trend ve Sabit Terimli & $-3,63891$ & $0,0292^{* *}$ \\
\hline \multirow{2}{*}{$\begin{array}{l}\text { Bankacılık Sektörü } \\
\text { Yurtiçi Kredi Büyümesi }\end{array}$} & Sabit Terimli & $-3,84025$ & $0,0030^{*}$ \\
\hline & Trend ve Sabit Terimli & $-3,40516$ & $0,0000^{*}$ \\
\hline \multirow{2}{*}{$\begin{array}{l}\text { Reel Kesim } \\
\text { Güven Endeksi }\end{array}$} & Sabit Terimli & $-4,51638$ & $0,0003^{*}$ \\
\hline & Trend ve Sabit Terimli & $-4,51187$ & $0,0019^{*}$ \\
\hline \multirow[b]{2}{*}{ Dış Ticaret Fazlası } & Sabit Terimli & $-2,70381$ & $0,0752^{* * *}$ \\
\hline & Trend ve Sabit Terimli & $-3,42176$ & $0,0525^{* * *}$ \\
\hline \multirow[b]{2}{*}{ İşsizlik Oranı } & Sabit Terimli & $-3,69568$ & $0,0049^{*}$ \\
\hline & Trend ve Sabit Terimli & $-3,69151$ & $0,0252^{* *}$ \\
\hline \multirow{2}{*}{$\begin{array}{l}\text { Uluslararası } \\
\text { Rezervler }\end{array}$} & Sabit Terimli & $-2,01307$ & 0,2811 \\
\hline & Trend ve Sabit Terimli & $-0,86987$ & 0,9561 \\
\hline \multirow[b]{2}{*}{ M2/Uluslararası Rezervler } & Sabit Terimli & $-1,64402$ & 0,4581 \\
\hline & Trend ve Sabit Terimli & $-1,93723$ & 0,6310 \\
\hline \multirow[b]{2}{*}{ Reel Borsa } & Sabit Terimli & $-2,207$ & 0,2046 \\
\hline & Trend ve Sabit Terimli & $-2,58265$ & 0,2888 \\
\hline \multirow[b]{2}{*}{ VIX Endeksi } & Sabit Terimli & $-2,98296$ & $0,0383^{* *}$ \\
\hline & Trend ve Sabit Terimli & $-3,16342$ & $0,0630^{* * *}$ \\
\hline \multirow[b]{2}{*}{ JP Morgan EMBI Endeksi } & Sabit Terimli & $-2,90752$ & $0,0463^{* *}$ \\
\hline & Trend ve Sabit Terimli & $-2,94737$ & 0,1502 \\
\hline \multirow[b]{2}{*}{ ABD 10 Yıllık Tahvil Getirisi } & Sabit Terimli & $-2,2114$ & 0,2030 \\
\hline & Trend ve Sabit Terimli & $-3,34031$ & $0,0630^{* * *}$ \\
\hline
\end{tabular}

${ }^{*} 0,001$ anlamlılık düzeyinde durağan; ${ }^{* *} 0,05$ anlamlılık düzeyinde durağan; ${ }^{* * *} 0,10$ anlamlılık düzeyinde durağan

Tablo 2: ADF Birim Kök Testi Sonuçları 
Çalıșma da faktör analizi ile yeni yapay değişkenler üretilirken alt yöntem olarak temel bileşenler analizi yöntemi kullanılmaktadır. Temel bileșenler analizi faktör analizinde olduğu gibi çoğunlukla yatay kesit verilere uygulanan bir yöntem olarak karşımıza çıkmaktadır. Zaman serisi verisine sahip değişkenlere temel bileșenler analizinin uygulanabilmesi için verinin durağan olması koşulu aranmaktadır. Çünkü yöntemde giriş matrisinin sütunları yani değişkenler arasındaki yüksek ilişki analiz edilmekte ve her bir sütunun satırları arasındaki (yani her bir değişken için gözlem birimleri arasındaki) ilişkiden en az miktarda etkilenmesi istenmektedir. Faktör analizi değişkenler arasındaki kovaryans veya korelasyon matrisi üzerine tesis edildiğinden, durağan olmayan zaman serilerinde ilişkisiz değişkenler arasında bile yüksek korelasyon gözlenebilmektedir. Diğer bir ifadeyle seriler durağan değilse, değișkenler arasında sahte korelasyon ortaya çlkmaktadır. Bu nedenle, veri matrisi durağan olmayan zaman serisi gözlemlerinden oluşuyorsa, temel bileşenler analizi tüm değişkenlere benzer ağırlıkları veren sadece bir veya en fazla birkaç yeni bileșen üretebilecektir (Lansangan \& Barrios, 2009,s.174:176). Bu durum finansal istikrar gibi birçok değişkenden etkilenen çok boyutlu ancak gözlenemeyen bir olgunun gözlenebilir ölçümü olarak elde edilen bileşenlerin yorumlanmasında yanıltıcı sonuçlara neden olabilmektedir. Çalışmada aylık zaman serisi verileri kullanıldığından faktör analizi öncesinde çalışma kapsamında yer alan değişkenlerin durağanlığı Geniş̧letilmiş DickeyFuller (ADF) birim kök testi ile sınanmıştır. ADF birim kök testi sonuçları Tablo 2'de verilmiştir.

Tablo 2 incelendiğinde Uluslararası rezervler, M2/Uluslararası Rezervler ve Reel Borsa değișkenlerinin durağan olmadığı yani diğer bir deyişle birim köke sahip olduğu görülmektedir. Söz konusu değişkenlerin yıllık büyümesi hesaplanmış ve ADF testi sonuçları yıllık büyüme oranlarının durağan olduğunu göstermiştir. Bu nedenle ilgili değişkenler için faktör analizinde yıllık büyüme oranları kullanılmıştır.

Faktör analizi arasında yüksek ilişki bulunan değişkenlerden ilişkisiz faktör adı verilen yeni yapay değişkenler üretmek için uygulanmaktadır. Bu doğrultuda faktör analizinin uygulanabilmesi için en önemli şartlardan bir tanesi değişkenler arasında yüksek ilişskinin bulunmasıdır ve bunun tespiti için küresellik testi uygulanmaktadır.

\begin{tabular}{|l|l|l|}
\hline \multicolumn{2}{|l|}{ Kaiser-Meyer-Olkin Örneklem Uygunluğu Ölçütü } & 0,599 \\
\hline \multirow{2}{*}{ Bartlett'in Küresellik Testi } & Ki-kare değeri & 1728,027 \\
\cline { 2 - 3 } & p değeri & $0,000^{*}$ \\
\hline
\end{tabular}

${ }^{*} 0,01$ anlamlılık düzeyinde yokluk hipotezi kabul edilememiștir.

Tablo 3: Küresellik Testi Sonucu

Tablo 3 incelendiğinde değişkenler arasında ilişki olmadığını iddia eden yokluk hipotezi reddedilmiştir ve bu sonuç söz konusu değişkenlere faktör analizinin uygulanabileceğini göstermektedir. Tablo 1 de listelenmiş olan değişkenlerin durağan düzeyleri ile 2002:2-2017:12 dönemi için faktör analizi yöntemi uygulanmış ve özdeğeri 1'den daha büyük olan 4 faktör elde edilmiştir. Değișkenlerin faktörlerle olan ilişkisi yükler matrisi olarak Tablo 4'de sunulmuştur. Değișkenlerin faktörlerle olan ilișkisi 
incelendiğinde; birinci faktör etrafında Bankacılık Sektörü Yurtiçi Kredi Büyümesi, Uluslararası Rezervlerdeki Artış Oranı, M2/Uluslararası Rezervlerdeki Artış Oranı, Reel Borsa Getirisi ve ABD 10 Yıllık Tahvil Getirisi değişkenlerinin, ikinci faktör etrafında Büyüme Oranı, Reel Kesim Güven Endeksi, İşsizlik Oranı, Dış Ticaret Fazlası, VIX Endeksi değişkenlerinin, üçüncü faktör etrafında Enflasyon Oranı, Getiri Farkı ve JP Morgan EMBI endeksinin; dördüncü faktör etrafında ise Borsa Oynaklığı ve Reel Efektif Döviz Kuru Oynaklığı değişkenlerinin toplandığı görülmektedir. Ayrıca değișkenlerin faktörlerle olan ilişkilerinde işaret yönleri dikkate alındığında, birinci ve ikinci faktörlerin finansal sistemdeki istikrarı; üçüncü ve dördüncü faktörlerin ise finansal sistemdeki istikrarsızlı̆̆a karşılık geldiği görülmektedir. Elde edilen faktörlerden finansal istikrarı gösterecek tek bir değişkenin oluşturulması hedeflenmektedir. Üçüncü ve dördüncü değişken istikrarsızlığı gösterdiği için -1 ile çarpılarak birinci ve ikinci faktörle toplanmıştır. Bu yolla elde edilen yeni değişken 2010=100 olacak şekilde endekse dönüştürülmüștür. Yukarıda açıklanan gerekçeler doğrultusunda temel devresi 2010 yılı olan endekse "finansal istikrar endeksi" adı verilmiştir.

\begin{tabular}{|l|l|l|l|l|}
\hline & \multicolumn{4}{|l|}{ Bileşenler } \\
\hline & $\mathbf{1}$ & $\mathbf{2}$ & $\mathbf{3}$ & $\mathbf{4}$ \\
\hline Enflasyon Oranı & 0,0995 & $-0,0475$ & 0,8934 & 0,2153 \\
\hline Getiri Farkı & $-0,0585$ & 0,2188 & 0,7332 & 0,0148 \\
\hline Büyüme Oranı & 0,3055 & 0,6935 & 0,2229 & $-0,2377$ \\
\hline Bankacılık Sektörü Yurtiçi Kredi Büyümesi & 0,6151 & 0,4250 & $-0,4834$ & 0,0912 \\
\hline Reel Kesim Güven Endeksi & 0,0563 & 0,6616 & 0,1073 & $-0,5065$ \\
\hline İșsizlik Oranı & $-0,0350$ & $-0,8730$ & 0,1129 & $-0,1339$ \\
\hline Dış Ticaret Fazlası & 0,4907 & $-0,5222$ & 0,4687 & 0,1894 \\
\hline Uluslararası Rezerv Artıșı & 0,6512 & 0,3974 & $-0,0293$ & 0,2584 \\
\hline M2/Uluslararası Rezervlerdeki Artış & 0,7777 & $-0,0220$ & $-0,0461$ & $-0,2440$ \\
\hline Reel Borsa Getirisi & 0,5945 & 0,1073 & $-0,2634$ & $-0,5262$ \\
\hline Borsa Oynaklığı & 0,0541 & $-0,1345$ & 0,0779 & 0,6885 \\
\hline Döviz Kuru Oynaklığı & 0,1033 & 0,0670 & 0,2133 & 0,6537 \\
\hline VIX Endeksi & $-0,1837$ & $-0,5397$ & 0,0968 & 0,5254 \\
\hline ABD 10 Yıllık Tahvil Getirisi & 0,8061 & 0,0512 & 0,3100 & 0,2504 \\
\hline JP Morgan EMBI & $-0,0634$ & $-0,3170$ & 0,6920 & 0,4644 \\
\hline
\end{tabular}

Tablo 4: Yükler Matrisi

Elde edilen finansal istikrar endeksinin zamana göre eğilimi Şekil 1'de verilmiştir. Şekil 1 incelendiğinde, 2002 yılında istikrarın düştüğü ancak 2002 Temmuz ayından sonra ekonominin toparlanmaya başladığı ve ortalama olarak 2004-2007 yılları arasında istikrarın sürdürdüğü görülmektedir. Buna karşın 2008 Eylül ayından sonra istikrar sert bir düşüş yaşayarak 2008 Kasım ayında en dip noktayı gördükten sonra tekrar yükselişe geçmiş ve 2010 yılından itibaren belirli bir seviyede devam etmiştir. Finansal istikrar endeksindeki azalış dönemlerin Türkiye Ekonomisini de etkileyen 2008 Global kriz dönemlerine karşıllk geldiği görülmektedir. Bu durum Türkiye için hesaplanan finansal istikrar endeksinin başarılı olduğuna işaret etmektedir. 


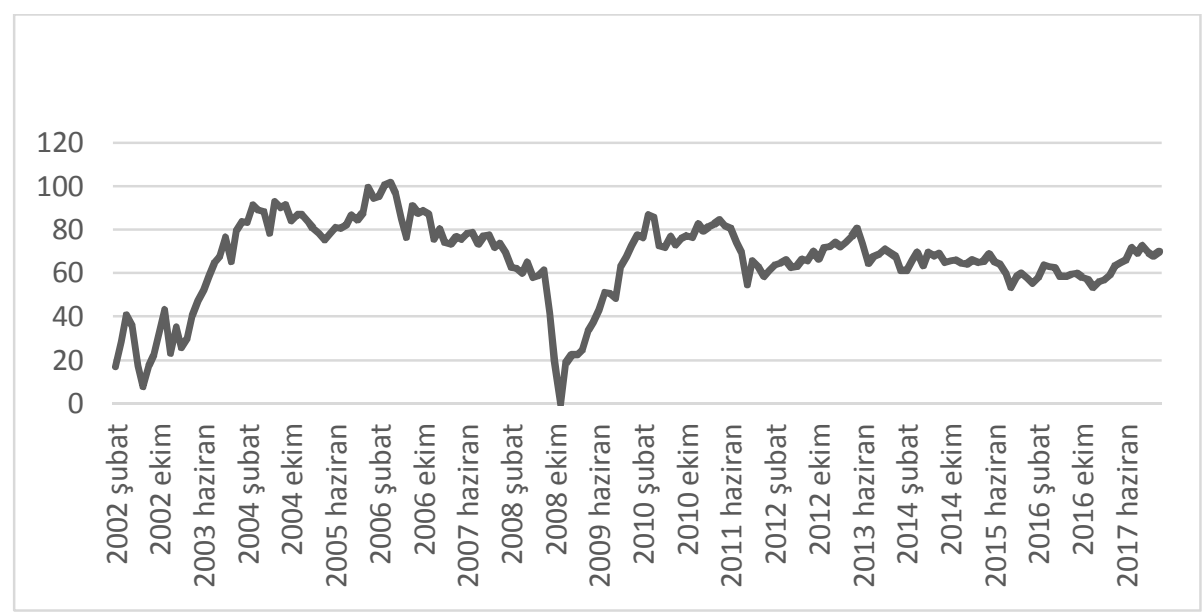

Şekil 1: Finansal İstikrar Endeksinin Zamana Göre Eğilimi

\section{Genişletilmiş Taylor Eşitliği: Kalman Filtresi Yöntemi ile Tahminler}

Klasik regresyon eşitliğinde açıklayıcı değiş̧kenlere ait katsayılara karşılık gelen parametrelerin sabit olduğu bilinmektedir. Sabit parametreli modeller ekonominin istikrarlı olduğu varsayımına dayanmaktadır. Ancak zaman serisi ekonometrisinde ekonomik kriz ve/veya politika değişikliği gibi nedenlerle parametreler zaman içerisinde değișebilir. Bu durumda elde edilen tahminler uygulanan para politikasının reaksiyonlarını doğru biçimde yansıtmayacaktır. Bu görüșten hareketle Telatar (2001) çalışmasında reaksiyon fonksiyonunu değişken katsayılı Markov-değişimli varyans modeli kullanarak tahmin etmiştir. Merkez bankalarının genişleme ve daralma dönemlerinde asitmetrik tepki gösterdiği yani reaksiyon fonksiyonunun asimetriliği ayrı bir tartışma konusu olarak karşımıza çıkmaktadır. Merkez bankalarının reaksiyon fonksiyonlarının asimetrik olabileceği ve doğrusal bir model seçildiği zaman, yapılan politika değișiklikleri, oluşan ekonomik krizler ve ekonominin yeniden yapılandırılması için gerçekleştirilen kurumsal değişiklikler doğrultusunda elde edilen sonuçların geçerli olamayacağından hareketle Omay ve Hasanov (2010) çalışmasında ve Hasanov ve Omay (2008) çalışmasında doğrusal olamayan reaksiyon fonksiyonunu tahmin etmiştir.

Çalışmada kullanılan aylık zaman serisi dönem aralığı dikkate alındığında, TCMB 2002 yılından itibaren önce örtük olarak uyguladığı enflasyon hedeflemesinden, 2006 yılından itibaren açık enflasyon hedeflemesi rejimine geçiş yapmıştır. Ayrıca, 2008 yılında yaşanan küresel ekonomik krizin Türkiye ekonomine yansımaları da olmuştur. Bu nedenle finansal istikrar ile genişletilmiş Taylor eşitliğinde parametrelerinin zamanla değiştiği varsayılmıștır. Zamanla değișen parametrelerin tahmin edilmesinde Kalman Fitresi Yöntemi kullanılmıştır. İncelenen dönem içerisinde çıktı açığının katsayısı sabit tutulmuş, enflasyon açığının ve finansal istikrar göstergesinin katsayılarının ise zamanla değiştiği varsayılmıştır. Parametreleri zamanla değişen genişletilmiş Taylor eșitliği aşağıdaki gibi tanımlanmıştır: 


$$
\begin{aligned}
& r_{\mathrm{t}}=\alpha_{0}+\alpha_{\mathrm{t}}\left(\pi_{\mathrm{t}}-\pi_{\mathrm{t}}^{*}\right)+\beta\left(\mathrm{y}_{\mathrm{t}}-\mathrm{y}_{\mathrm{t}}^{*}\right)+\gamma_{\mathrm{t}} \mathrm{fs}_{\mathrm{t}}+\mathrm{u}_{\mathrm{t}} \\
& \alpha_{t}=\alpha_{t-1}+e_{1 t} \\
& \gamma_{t}=\gamma_{t-1}+e_{2 t}
\end{aligned}
$$

Burada $\alpha_{t}$ ve $\gamma_{t}$ zamana bağlı olarak değișen parametre vektörleridir ve $e_{j t}$ j=1,2 hata terimidir. (3) numaralı eşitlik ölçüm denklemi, (4) ve (5) numaralı eşitlikler durum denklemleridir. Genel yaklaşıma göre hata terimleri olan $e_{j t} u_{t}$ bağımsız ve ortalaması sıfır, sabit varyanslı normal dağılıma sahiptir. Enflasyon için Tüketici Fiyat Endeksinde (TÜFE) bir önceki yılın aynı dönemine göre yüzde değişim, hedeflenen enflasyon için ise Merkez Bankası 12 Ay Sonrasının Yıllık TÜFE Beklentisi (\%)-Düzey serisi kullanılmıștır. Bu iki değişkenin farkı hesaplanarak enflasyon açığı olarak analize dâhil edilmiştir. Çıktı açı̆̆ı gözlenen üretim seviyesi ile potansiyel üretim arasındaki fark olarak tanımlanmaktadır. Potansiyel üretimin hesaplanmasında genellikle HodrickPrescott Filtreleme, Kesirli Filtreleme, Karesel Beveridge Nelson Filtreleme ve Kalman Filtreleme gibi alternatif filtreleme yöntemleri kullanılmaktadır. Çalıșmada, GSYİH değişkeni aylık frekanslı olarak yayınlanmadığından, üretim değişkeninin vekili olarak Sanayi Üretim Endeksi kullanılmıştır. Sanayi Üretim Endeksi Tramo/Seats yöntemi ile mevsimsel etkiden arındırılmış ve daha sonra Hodrick-Prescot yöntemi ile elde edilen doğrusal trendden sapmalar hesaplanarak çıktı açı̆̆ı elde edilmiştir. Kalman yöntemi ile elde edilen sonuçlar Tablo 5’te verilmiştir.

\begin{tabular}{|l|l|l|l|}
\hline & Katsayı & Std. Hata & P değeri \\
\hline Sabit Terim & -0.259 & 0.226 & 0.2524 \\
\hline Enflasyon Açı̆̆ı & 2.753 & 0.160 & $0.000^{*}$ \\
\hline Çıktı Açı̆̆ı & 4.289 & 0.087 & $0.000^{*}$ \\
\hline Finansal İstikrar Göstergesi & 0.122 & 0.009 & $0.000^{*}$ \\
\hline
\end{tabular}

* 0.01 anlamlılık düzeyinde anlamlı

Tablo 5: Taylor Modeli Tahmin Sonuçları

Fisher teorisine göre nominal faiz reel faiz ve enflasyonun bir fonksiyonudur. 0 halde enflasyon oranlarındaki artış karşısında merkez bankası enflasyonu kontrol altına alabilmek için kısa vadeli nominal faiz oranlarını artıracaktır. Öte yandan Taylor Kuralına göre enflasyon açığı ve çıktı açığı ile faiz oranları arasında pozitif bir ilişki söz konusudur.

Gelişmekte olan ülkelerde küresel risk iştahının yüksek olduğu, sermaye girișinin sağlandığı ekonominin canlandırılma dönemlerinde, döngüsel para politikası izleyen merkez bankaları kısa vadeli faiz oranlarını düşük tutmaktadır. Bu sayede tasarruf eğilimi azalarak yatırımlar artacak, sermaye akışı hızlanacak ve ekonomi tekrar canlanacaktır. Dolayısıyla ekonomide aşağı yönlü risklerin belirdiği ekonomik 
istikrarsızlığın arttığı bu dönemlerde merkez bankasının kısa vadeli faiz oranını da düşürmesi beklenmektedir. Yani finansal istikrar göstergesi ile faiz oranı arasında da pozitif yönlü bir ilişki beklenmektedir (Dağlaroğlu, Demirel \& Mahmud, 2017). Elde edilen parametre tahminleri beklentiye uygun ve istatistiksel olarak anlamlıdır.

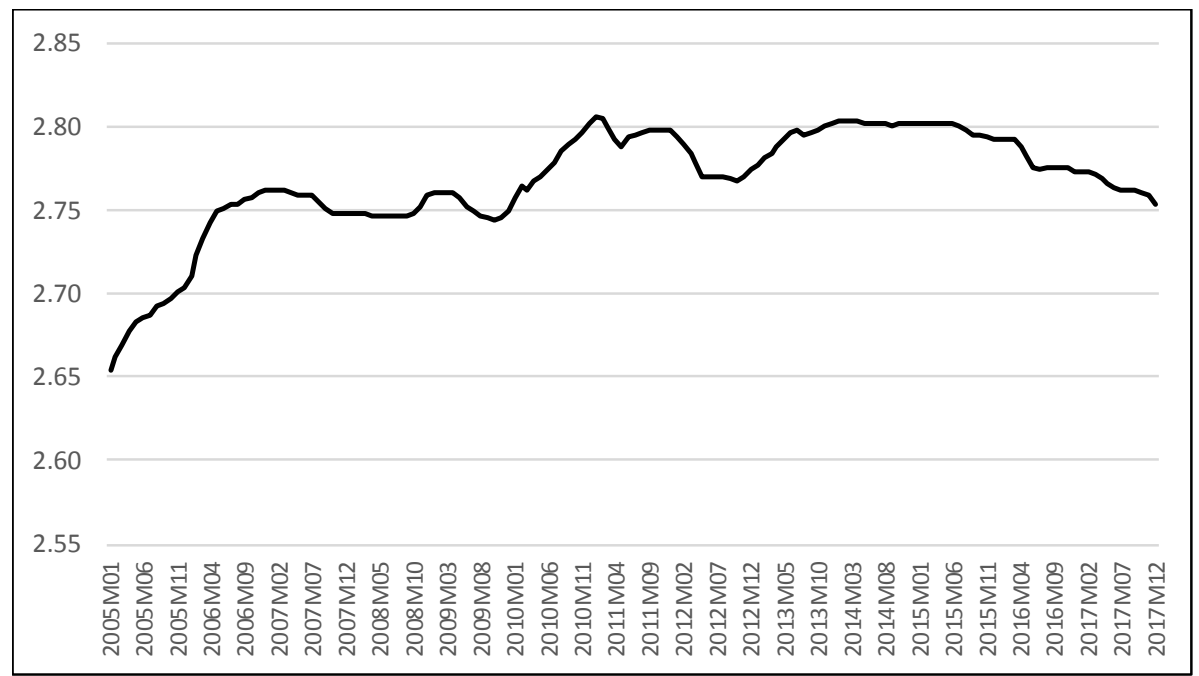

Şekil 2: Enflasyon Açığı Katsayısının Zamana Göre Eğilimi

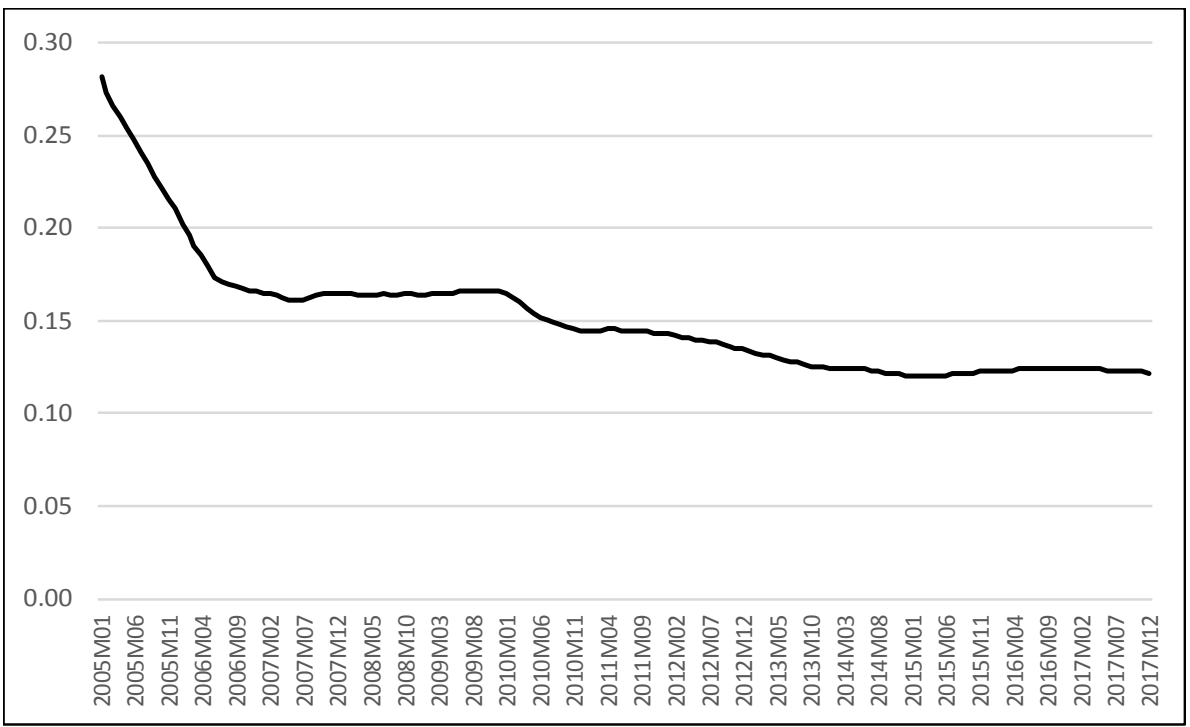

Şekil 3: Finansal İstikrar Katsayının Zamana Göre Eğilimi

Kurulan modelde enflasyon açığı ve finansal istikrar endeksi değişkenlerine ait katsayıların zamana bağlı olarak değiștiği varsayılmıștır. Bu parametrelerin Kalman 
Filter tahminlerinin zamana göre eğilimleri Şekil 2 ve Şekil 3'te verilmiştir. TCMB 2002 yılından beri örtük enflasyon hedeflemesi uygularken 2006 yılında resmi olarak enflasyon hedeflemesi rejimi uygulamaya başlamıştır. 2010 yılında ise yine politika değişikliğine giderek finansal istikrarı ikinci bir hedef olarak gözetmeye başlamıştır. Parametre tahminlerinin zamana bağlı olarak değișimi incelendiğinde özellikle 2006 yılında ve 2010 yılındaki değişimleri yansıttığı açıkça görülmektedir. Ayrıca 2005 yılından itibaren finansal istikrar endeksine ait katsayı tahmin değerlerinin azalma eğilimine girdiği ve 2010 yılından sonraki dönemlerde kararlılık gösterdiği gözlenmiştir. $\mathrm{Bu}$ durum 2010 yllından itibaren TCMB tarafından politika faiz oranlarının belirlenmesinde finansal istikrarın kararlı bir șekilde dikkate alındığına işaret etmektedir.

\section{Sonuç}

Merkez bankalarının öncelikli hedefi fiyat istikrarını sağlamaktır. Ancak finansal sistem de meydana gelebilecek olası bir istikrarsızlık bütün ekonomiyi etkilemekte ve nihayetinde merkez bankalarının hedefi olan fiyat istikrarını da bozmaktadır. Özellikle 2008 küresel krizin ardından para politikası ve finansal istikrar arasındaki ilişki önemli bir konu olarak gündeme gelmiştir. Merkez Bankaları fiyat istikrarına odaklanırken finansal sistemde biriken risklerin göz ardı edilmemesi, ekonominin gidişatı ve para politikasının sürdürülebilirliği açısından önem arz etmektedir. 2010 yılından sonra TCMB yeni makro ihtiyati tedbirler almış ve finansal istikrarı sağlamayı ve sürdürmeyi ikincil bir hedefi kabul ederek koridor sistemine geçmiştir.

Bu çalışmada iki önemli konu üzerinde durulmuştur. Birincisi finansal istikrarı tanımlayacak veya ölçecek nitelikte literatürde kabul görmüş bir göstergenin oluşturulmamış olması literatürde bir tartışma konusu olarak karşımıza çıkmaktadır. Bu çalışmada da öncelikli olarak bu tartışmaya katkı sunulmak üzere bir göstergenin oluşturulması hedeflenmiștir. 2002-Şubat:2017-Aralık dönemi için farklı sektörleri temsilen dâhil edilen birçok makro gösterge toplulaștırılarak "finansal istikrar endeksi" oluşturulmuştur.

Son zamanlarda sıkça karşımıza çıkan diğer bir tartışma konusu ise merkez bankalarının para politikalarını belirlerken finansal istikrarı göz önünde bulundurması gerektiğidir. Elde edilen finansal istikrar göstergesi ile Taylor kuralına dayalı para politikası modeli genişletilerek; TCMB’nin finansal istikrarı gözetip gözetmediği değerlendirilmiştir. Model parametreleri Kalman yöntemi ile tahmin edilmiştir. Bu yöntemin kullanılmasının en önemli avantajı merkez bankasının faiz kararında finansal istikrardan etkilenip etkilenmediğinin yanında, para otoritelerinin finansal durumdan etkilendiği dönemlerin de tespit edilebiliyor olmasıdır. Elde edilen ampirik bulgular, genişletilmiş Taylor eşitliğinde enflasyon ve çıktı açıklarına ait katsayıların yanı sıra finansal istikrar katsayısının da istatistiki olarak anlamlı olduğunu göstermiștir. Bu sonuç politika faiz oranının belirlenmesinde sadece fiyat istikrarı ve üretim açı̆̆ının değil aynı zamanda finansal istikrarın da TCMB tarafından dikkate alındığına işaret etmektedir. 
Türkiye gibi gelişmekte olan ülkeler ekonominin de küreselleşmesi ile birlikte sermaye akışını sağlamak için esnek döviz kuru rejimine geçmiştir. Böylece merkez bankaları kısa dönem faiz oranlarını belirlerken yurtiçi göstergeleri dikkate alarak hareket edebilmişlerdir. Birçok ekonomik değişkenin bir araya toplanarak finansal istikrar göstergesinin elde edilmiş olması olası risklerin aynı anda değerlendirilmesi şansını tanımıştır. İncelenen dönem içerisinde elde edilen bulgular göstermiştir ki enflasyon oranlarının arttığı, büyümenin azaldığı, küresel risk iştahının artarak ekonomideki istikrarın azaldığı dönemlerde ekonomiyi canlandırmak ve sermaye akışını hızlandırmak için kısa dönem faiz oranlarını azaltmıştır. Yani sadece fiyat istikrarını değil finansal istikrarı da gözeterek para politikasını belirlemiştir.

Elde edilen gösterge içerdiği değişkenler itibari ile değerlendirildiğinde her zaman geliştirilmeye açıktır. Ekonominin genel gidişatı ve gelişimine bakılarak farklı değişkenler dâhil edilebilir veya hali hazırda kullanılan bazı değișkeler zamana bağlı olarak analiz dışında tutulabilir. Finansal istikrar göstergesi farklı yöntemlerle de elde edilebilir. Finansal istikrar göstergesinin geliștirilmesi sonlanmayacak bir tartışma konusu olarak devam edecektir. Küreselleșen ekonomi ile birlikte diğer ülkelerin de analize dâhil edilerek birlikte ele alınması fikri gelecek çalışmalara ışık tutacaktır.

\section{KAYNAKÇA}

ADOLFSON, M. (2007). Incomplete exchange rate pass-throught and simple monetary policy rules. Journal of International Money and Finance, 468-494. AKRAM, Q. F., BÅRDSEN, G., \& LINDQUIST, K.-G. (2007). Pursuing Financial Stability Under An Inflation-Targetting Regime. Annals Finance, 131-153.

AKTAȘ, C. (2011). Finansal İstikrar Analizi Bağlamında Türkiye için Finansal İstikrar Endeksi Önerisi. Doktora Tezi. Ankara: Ankara Üniversitesi, Sosyal Bilimler Enstitüsü.

ALBULESCU, C. T. (2013). Financial Stability and Monetary Policy: A ReducedForm Model For The Euro Area. Romanian Journal of Economic Forecasting, 62-81.

ALLEN, W. A., \& WOOD, G. (2006). Defining and Achieving Financial Stability. Journal of Financial Stability, 152-172.

ARDOR, H. N., \& VARLIK, S. (2014). İleriye Dönük Yeni Keynesyen Para Politikası Reaksiyon Fonksiyonunun Tahmini: Taylor Kuralı'nın, Mccallum Kuralı'nın, TaylorMccallum Melez Kuralı'nın Türkiye Ekonomisinde Geçerliliği. Ekonomik Yaklaşım, 24(89), 45-71.

BALL, L. (1999). Policy Rules for Open Economies. E. John B. Taylor içinde, Monetary Policy Rules (s. 127-156). University of Chicago Press.

BAŞÇI, E., \& KARA, H. (2011). Finansal İstikrar ve Para Politikası. Íktisat İşletme ve Finans, 26(302), 9-25.

BAUDUCCO, S., BULÍŘ, A., \& ČIHÁK, M. (2008). Taylor Rule Under Financial Instability. IMF Working Paper. International Monetary Fund. 
BAXA, J., HORVÁTH, R., \& VAŠÍČEK, B. (2013). Time-varying monetary policy rules and financial stress: Does financial instability matter for monetary policy? Journal of Financial Stability, 117-138.

BERNANKE S. Ben. ve Frederic S. MISHKIN. (1997). Inflation Targeting: A New Framework for Monetary Policy?. NBER Working Paper No. 5893, Cambridge, Massachusetts: National Bureau of Economic Research.

CARARE, A., SCHAECHTER, A., STONE, M., \& ZEMLER, M. (2002). Establishing Initial Conditions in Support of Inflation Targeting. IMF Working Paper No.02/102. Washington: International Monetary Fund.

CASTRO, V. (2011). Can central banks' monetary policy be described by a linear (augmented) Taylor Rule or by a nonlinear rule? . Journal of Financial Stability, 228-246.

CEVIK, E. I., DİBOOGLU, S., \& KENC, T. (2016). Financial stress and economic activity in some emerging Asian economies. Research in International Business and Finance, 127-139.

ÇETIN, M. Ö. (2016). Türkiye Cumhuriyet Merkez Bankası (TCMB) Para Politikası Uygulamalarının Gelișimi. Finansal Araştırmalar ve Çalışmalar Dergisi, 8(14), 67-101.

DAĞLAROĞLU, T., DEMİREL, B., \& MAHMUD, S. F. (2017). Monetary policy implications of short-term capital flows in Turkey. Empirica.

DAS, U. S., PAPAPIOANNOU, M., PEDRAS, G., AHMED, F., \& Surti, J. (2010). Managing Public Dept and Its Financial Stability Implications. IMF Working Paper No.10/280. Washington: International Monetary Fund.

FERRUCCI, G., HERZBERG, V., SOUSSA, F., \& TAYLOR, A. (2004). Understanding Capital Flows to Emerging Market Economies. Bank of England Financial Stability Review Issue.16. London: Bank of England.

FREEDMAN, Charles. ve Inci OTKER-ROBE. (2010). Important Elements for Inflation Targeting for Emerging Economies. IMF Working Paper No. 10/113,2010.Washington: International Monetary Fund.

GARCIA, C. J., RESTREPO, J. E., \& ROGER, S. (2011). How much should inflation targeters care about the echange rate? Journal of International Money and Finance., 1590-1617.

HAMMOND, Gill. (2012). State of the Art of Inflation Targeting-2012. Centre for Central Banking Studies Handbook-No.29.Bank of England.

HASANOV, M., \& OMAY, T. (2008). Monetary policy rules in practice: Reexamining the case of Turkey. Physica A(387), 4309-4318.

ILLING, M., \& LIU, Y. (2003). An Index of Financial Stress for Canada. Working Paper 2003-14. Bank of Canada.

IŞIK, S., DUMAN, K., \& KORKMAZ, A. (2004). Türkiye Ekonomisinde Finansal Krizler: Bir Faktör Analizi Uygulaması. D.E.Ü.İ.I.B.F. Dergisi, 19(1), 45-69.

JEANNEAU, S., \& MICU, M. (2002). Determinants of International Bank Lending to Emerging Market Countries. BIS Working Paper No.112. Basel: Bank for International Settelements.

JOHNSON, R. A., \& WICHERN, D. W. (2007). Applied Multivariate Statistical Analysis (Six Edition b.). New Jersey: Pearson Prentice Hall. 
KÄFER, B. (2014). The Taylor Rule and Financial Stability: A Literature Review with Application for the Eurozone. Joint Discussion Paper Series in Economics.

KARA, H. A. (2012). Küresel Kriz Sonrası Para Politikası. TCMB Çalışma Tebliği, 12(17). Ankara: Türkiye Cumhuriyet Merkez Bankası.

LANSANGAN, J. R., \& BARRIOS, E. B. (2009). Principal Components Analysis of Nonstationary Time Series Data. Statistics and Computing, 19(2), 173-187.

MONTAGNOLI, A., \& NAPOLITANO, 0. (2005). Financial Condition Index and Interest Rate Settings: A Comparative Analysis. Working Paper N., 8. Universitá Degli Studi di Napoli "Parthenope" Instituto di Studi Economici.

OMAY, T., \& HASANOV, M. (2010). Türkiye için Reaksiyon Fonksiyonunun Doğrusal Olmayan Modelle Tahmin Edilmesi. Cankaya University Journal of Humanities and Social Sciences, 7(2), 467-490.

ROZADA, M. G., \& YEYATI, E. L. (2006). Global factors and emerging market spreads. Inter-American Development Bank Research Department Working Paper No:552. Washington DC: Inter-American Development Bank.

SVENSSON, L. E. (2000). Open economy inflation targeting. NBER Working paper No.6545. Cambridge: National Bureau of Economic Research.

SVENSSON, L. E. (2002). Inflation targeting: Should it be modeled as an instrument rule or a targeting rule? European Economic Review, 771-780.

TELATAR, E. (2001). Para Arzı Reaksiyon Fonksiyonunun Değişken KatsayılıDeğişken Varyans Modeli ile Tahmini. H.Ü. İktisadi ve İdari Bilimler Fakültesi Dergisi, 19(2), 1-17.

TAYLOR, J. B. (1993). Discretion Versus Policy Rules in Practice. CarnegieRochester Conference series on Public Policy, 195-214.

WOODFORD, M. (2012). Inflation Targeting and Financial Stability. Cambridge: National Bureau of Economic Research.

\section{Summary}

In 1990, New Zeland firstly introduced Inflation Targeting Regime to the World and then several countries started to apply Inflation Targetting Regime to fight aganist inflation. Central Bank of Republic of Turkey (CBRT) also has been implemented implicit inflation targeting regime since 2001 and inflation targeting regime since 2006 to pressure the inflation. Primary aim is to provide price stability with using inflation targeting regime. However, after the global crisis in 2008, it was detected to importance of financial stability. In other words, financial stabilty and price stabilty should be evaluated together to regulate the inflation. In this way, CBRT started to regard financial stability in 2010 as second aim of monetary policy. However, there is no accepted description and measured approach to define financial stabilty, although many studies has been performed. Main reason of the this unclear situation is the dynamic nature of the financial stability which changes depending on the time. 
In this study, financial stability index for the term 2002:M2-2017:M12 was constructed. When any financial stability indicator is constructed, whole economic system must be evaluated jointly, discussed multidimesional and several factors must be considered together. In addition to the main variables that comprise the financial system, the variables that reflect the state of the real economy should be considered. In this study, when the financial stability index was constructed, inflation rate, yield spread, growth rate, banking sector domestic loan growth, real sector confidence index, unemployment rate, foreign trade surplus, increase rate international rezerves, increase rate of money supply in international reserves, return on real exchange, stock market volatility, real effective exchange rate volatility, VIX index, USA 10-year bond yields and JP Morgan EMBI variables were analized by Factor Analysis Method. Factor Analysis Method usually use cross-section data and if time series data is used, then these variables must be stationary; so at beginning of emprical study unit root test were applied, then financial stability index was constructed by Factor Analysis Method and then Taylor rule was augmented by that index. Augmented Taylor Rule model parameters were estimated by Kalman Filter Method. Because of change in monetary policy strategy within the period examined, Kalman Filter Method which is time-varying parameter estimation method was used. Our result shows that financial stability coefficient is statistically significant as well as inflation gap and output gap. In other words monetary policy rule was influenced by financial stability. Especially in the period when inlation rate rised, growth rate reduced, global risk appetite rised and eventually financial stability decreased, CBRT reduced the short term interest rate to stimulate economy and ensure the capital flow. 